\title{
A Game Analysis of Cooperative Relationship Between Enterprises on Supply Chain
}

\author{
Yanli Guo \\ Business College, Beijing Union University, Beijing 100025, P.R. China \\ Yanli.guo@bcbuu.edu.cn
}

\begin{abstract}
Cooperation is the essence of supply chain. All members of the supply chain cooperate and band together to create more value than that of each member can do, and to realize the whole value of supply chain, which is far greater than the simple sum of every link value. Cooperative efforts and collaborations between these enterprises make it easier to realize the whole benefit of supply chain and to improve their competitive ability. The relationships among these members or enterprises have direct link to the efficiency and benefit of supply chain. But it is dynamic and unstable, and often causes the instability of supply chain. So it is very important to analyze and management their cooperative relationship. In this essay, we try to use game theory to study the cooperative relationship between enterprises on supply chain. By studying the game theory, we try to establish the game model of their cooperative relationship, and then discuss the existence of equilibrium in this game. We also try to resolve two problems: how to establish stable cooperativerelationship and how to make it helpful to supply chain.
\end{abstract}

Keywords: Supply chain, Enterprises, Cooperative relationship, Game

\section{INTRODUCTION}

With the development of information technology, the traditional organization structure and the competition mode took place a huge change, the supply chain alliance as a kind of new form is popular, and the competition between different chains also became a main competitive mode. Faced with such competition environment, enterprises have to reconsider their strategies. They all establish supply chain or join some supply chain alliances in order to get ahead. In a supply chain, products or services move from the upstream suppliers, through some intermediate links, to the downstream sellers, and ultimately to the end users. In this process, all enterprises must cooperate and band together, or can not complete. And only cooperation can help them to realize the whole value of supply chain. So the essence of supply chain is cooperation, then cooperation and cooperative relationship is not separated. The relationship among enterprises have direct link to the efficiency and benefit of supply chain. More stable the cooperative relationship is, more steady the supply chain is and more efficient. But supply chain is a kind of strategic alliance of competition and cooperation coexisting [1]. Every enterprise hopes to maximize their profits. The cooperative relationship between them is often unstable and supply chain

Please use the following format when citing this chapter:

Guo, Y., 2007, in IFIP International Federation for Information Processing, Volune 255, Research and Practical Issues of Enterprise Information Systems II Volume 2, eds. L. Xu, Tjoa A., Chaudhry S. (Boston: Springer), pp. 1319-1323. 
is often dynamic. Generally speaking, establishment of cooperative relationship is decided by cooperative income and risk. We use game theory to discuss this problem.

\section{MAKING THE GAME MODEL}

The game theory of frog singing is a special limited reasonableness game model [2]: In frog mating season, the loud singing is an important tool that male frog draw on attention of female and get mating opportunity. But it also brings risk, such as exposure to snake and consuming its precious energy. And no-singing male frog may "hitch a ride" while face no risk. When the proportion of singing frog is at a lower level, more and more male frog vary from no-singing to singing, but when it exceed certain proportion, part of them vary from singing to no-singing increasingly, ultimately the proportion returns equilibrium finally. The game of frog singing and the supply chain management have great similarity. Each enterprise is a limited reasonableness individual. It is also a game problem that enterprises, as independent interest body, choose cooperation or no cooperation. So we can establish game model (table1.). Suppose: under the limited reasonableness condition, we randomly take enterprise 1 and enterprise 2 respectively from two types of enterprise communities 1 and 2 .

Table 1. Cooperation Game Model

\begin{tabular}{|c|c|c|c|}
\hline \multicolumn{4}{|c|}{ Enterprise 2} \\
\hline \multirow{3}{*}{ Enterprise 1} & & cooperate & No \\
\hline & cooperate & $\mathrm{p}-\mathrm{z}, \mathrm{p}-\mathrm{z}$ & $\mathrm{m}-\mathrm{z}, \mathrm{1}-\mathrm{m}$ \\
\hline & No & $1-\mathrm{m}, \mathrm{m}-\mathrm{z}$ & 0,0 \\
\hline
\end{tabular}

In the table, the benefit $m(0.5<m<1)$ and $p(\mathrm{~m}<\mathrm{p}<1)$ means cooperation income, the $z$ means cooperation risk.

See from the model, whether an enterprise would like to establish cooperative relationship is decided by the income and risk. Suppose in a supply chain the proportion of cooperative enterprises is $x$, and its change is decided by the original proportion and benefits. The more enterprises choose cooperation, the more benefits these enterprises acquire, and the larger $\mathrm{x}$ is. So we can get the replication dynamic equation:

$$
\frac{d_{x}}{d_{t}}=x(1-x)\{x(p-z-1+m)+(1-x)(m-z-0)\}
$$

Make $\frac{d_{x}}{d_{t}}=0$ get $\mathrm{x}^{\prime}=0, \mathrm{x}^{\prime}=1$ or $\mathrm{x}^{\prime}=(\mathrm{m}-\mathrm{z}) /(1-\mathrm{p})$

The equation has three stable points: $x^{\prime}=0, x^{\prime}=1, x^{\prime}=(m-z) /(1-p)$.According to the character of equilibrium strategy, a stable point can be called the equilibrium or stable strategy only if it has steadiness to small interference, i.e. being a stable strategy, $x$ ' not only is balanced state but also has such character that if some players deviates it because of accidental mistake, $x$ can be recovered to $x$ in the course of dynamic duplicating. We can regard three kinds of value of $m, z$, and $p$ as three kinds of different cooperation environment state (Figure1.) 
A Game Analysis of Cooperative Relationship Between Enterprises on Supply Chain

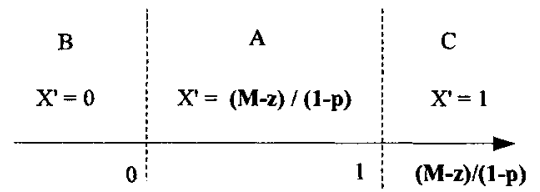

Figure 1. Cooperation Environment State Zones

\section{THE ESTABLISHMENT OF COOPERATIVE- RELATIONSHIP}

Belong to regardless which state above (figure 1.), the sizes of cooperation risk influence directly to establishment of cooperative relationship.

Obviously, both $\mathrm{B}, \mathrm{C}$ zone belong to lasting stable state, they will remain stability unless $z, m$ or $p$ changed.

When $(m-z) /(1-p)<0, x^{\prime}=0 x^{\prime}=1$ is reasonable, but in this state, $m<z$, i.e. cooperation profit be less than cooperation risk, so $x^{\prime}=0$ is only a stable strategy. (Figure.1 B) Obviously, in order to avoid risk no enterprise would like to cooperate. If we want to make this state mutate, and make enterprise change idea, we must change the ratio of $m$ to $z$, i.e. we must lower cooperation risk or increase profit.

When $(m-z)(1-p)>1, \quad x^{\prime}=0, x^{\prime}=1$ are reasonable. But in this state, $m-z>1-p$, because $p<1$, so $m>z$, only $\dot{x}=1$ is a stable strategy.(figure1.C) i.e. cooperation risk is smaller than cooperative income, as long as choose cooperation an enterprise can get benefits and take hardly risk. So most enterprises will choose cooperate. As long as the ratio of $m$ to $z$ doesn't change greatly, the cooperative relationship will be stable and the risk under control. Under this state, the cooperation risk is mainly decided by the sound degree of cooperative mechanism, about encouragement and adjustment, about benefits allotting and risks sharing, and by the conflict of different culture and target.

Comparatively, the A zone is a kind of unsteady state, or can be called as dynamic stable state. When $0<(m-z) /(1-p)<1$, all three stable points are reasonable, but only $x=(m-z) /(1-p)$ is a stable strategy. (Figure 1. A) It is in accord with the development of supply chain. There are a handful of enterprises in the community firstly to make a decision of establishing a cooperative supply chain riskily, and they acquire benefits from it, there will be other enterprises to imitate, so the proportion of cooperation enterprise will increase, but when it exceed $(m-z) /(1-p)$, even up to $100 \%$, then uncertain factors increase and cooperation risk grow, the opportunity cost of no cooperation decrease, some enterprises even can get more benefits through no cooperation. No cooperation variations appear and the proportion returns to the stable points.

There are a lot of risk factors in this case, and their impact on the establishment of cooperative relationship is tremendous. The variety of risk probably makes this cooperation environment state break into the $\mathrm{B}$ or $\mathrm{C}$ zone. Once cooperation risk exceeds cooperative income, the cooperative relationship will break and the 
establishment of supply chain then will die. If cooperation risk can be lowered or transferred effectively, and cooperative income is far larger than cooperation risk, the cooperative relationship can be stable state. So both states discussed above just are extreme states within certain time, we can see it as variation of the A zone under different space-time and it can represent the general realistic condition.

According to analysis of the game model, in the dynamic cooperative state, cooperative risk is the key of establishing stable cooperative relationship. Then many things influence the size of cooperative risk directly such as cooperative opportunity, the number and the ability of partnership, and the proportion of cooperative enterprises, and the time to participate. While there are a handful of enterprises start to try to establish supply chain system, the opportunity is in the ascension period, the quantity of partnership is also grow, enterprises choosing to join cooperative organization may get more benefits, of course, have to pay effort and take risk together with creator. When the more enterprises would like to choose cooperation and have an ability to take ego as core to build up supply chain, the more cooperative opportunity there are and the more partnership can be chose also. At the same time uncertain factor increases. Whichever enterprise, need choose to cooperate with whom, how and when, so must think over the ability of partnership, the whole market circumstance and the need of oneself etc. Maybe, it is a valid method of evading risk to build up a cooperative relationship with suitable object; otherwise risk and loss may be brought. When the proportion of cooperative enterprises exceeds the fixedpoint: $(m-z) /(1-p)$, another thing appears. Parts of enterprises benefit from the beneficial environment other enterprises create, for example profession standard, operating norm and management system etc. Gradually some enterprises is aware of that their experiences accumulated through cooperating have already been good enough to help them build up a supply chain which take oneself as core, so they don't fulfill strictly the contract any longer, and even change slowly from cooperation to no. Withdraw of partnership will strikes establishment and operation of a supply chain badly, making all enterprises face risk. So if the proportion of cooperative enterprises is over the stable state the higher cooperation risk may be brought. So to establish cooperative relationship we must take reasonable member quantity into consider, or it is hard to avoid fish in troubled waters. We should maintain the proportion of cooperative enterprises at the (M-Z)/ (1-P) stable point as far as possible. In addition, we should choose the good cooperative time and suitable partnership.

\section{KEEPING THE STABILITY OF COOPERATIVE- RELATIONSHIP}

According to above analysis, we must consider all kinds of cooperative risk in order to establish stable cooperative relationship. Through decreasing risks and insuring the cooperative environment is in the zone $\mathrm{C}$, we can keep the stability of cooperative relationship to some extent. But besides to choose good time, suitable partnership and so on, we can keep or improve the stability of cooperative relationship by establish long-term cooperation. 
Long-term cooperation is helpful for every member to improve their benefit and decrease uncertainty. In a supply chain, through long-term cooperation and trade, all of the members can make decisions under the condition that they know about one another to some extent. Even they can carry on a cheap "negotiation" with one another before making a choice. So it will strengthen sincerity and improve the cooperative environment.

Similarly, establishment of long-term cooperative relationship is a process of many members game repeatedly. To some degree, in a supply chain, each member has to make decisions or choices again and again [3] and has many chances to cooperate with others. As a rule, the behaviors and performances of the first cooperation have direct influence on the following one. If the first cooperation satisfies all players, it will be very smooth too to cooperate again. If one or some players don't feel satisfactory in one or some cooperation, it is almost impossible to cooperate again. Furthermore, maybe, in the course of long cooperation, all players will know the full history of others [4]. That is, we suppose that information is complete, and the behaviors taken by players some time ago or long ago become the public information, so, if he has a history of insincerity, no one would like to take the risk of cooperating with him, an untrustworthy fellow. Even if the information is incomplete (in reality, it often so), the players can select partners though many times cooperation. If they find anyone have insincere and default behaviors in the process of their cooperation they will punish him and end the partnership relation and eliminate him from the cooperative group. Taking his long-term benefit and credit in the trade into consideration, maybe a rational member will choose sincerity and try to establish long term cooperation; consequently, the stability of cooperative relationship will be kept.

\section{REFERENCES}

1. H. Kotzab and C. Teller, Value-adding partnerships and cooperation models in the grocery industry, International journal of physical distribution \& logistics management. Volume 33, Number 3, pp.268-281, (2003).

2. Y. Liu, The game of frog singing analysis about the supply chain management, China circulation economy. Number 1, pp.12-15, (2005).

3. X. Zha and Y. Guo, Game Analysis of Cooperative Behaviors Based on Third-Party Logistics, in Proc. of the Fifth Wuhan International Conference on E-Business, eds. Frank G. Duserick (Alfred University press: Alfred, NY 2006), pp.1145-1151.

4. G.P. Cachon and S. Netessine, Game theory in supply chain analysis, in Supply Chain Analysis in the eBusiness Era (Kluwer, 2003). http://www.ise.ufl.edu/shen/handbook/ (Accessed March 10, 2007).

5. J. Eriksson, N. Finne, and S. Janson, Evolution of a supply chain management game for the Trading Agent Competition, Al Communications. Number 19, pp.1-12, (2006).

6. X. Zha and Y. Guo, Study on the Mode of Cooperative SCM based on Demand Driving, in Proceedings of 2005 International Conference on Management Science \& Engineering, eds. H. Zhang, R. Zhao, and L. Chen (Orient Academic Forum: Marrickville, NSW, 2005), pp.847-851. 